\title{
Discussion on the Design of Electrical Energy-Saving Engineering in Intelligent Building
}

\author{
Jian Yin ${ }^{1}$, Junqin Liu ${ }^{2}$, Jing Yang ${ }^{3 *}$, Tao Lyv $^{4}$, Xiaohan Zhang ${ }^{3}$ \\ ${ }^{1}$ School of Civil Engineering, Henan Polytechnic University, Jiaozuo City 454003, Henan Province, China \\ ${ }^{2}$ Changsha University of Science and Technology, Changsha 410114, Hunan Province, China \\ ${ }^{3}$ School of Navigation, Shandong Jiao Tong University, Weihai City 264200, Shandong Province, China. \\ E-mail: 741655109@qq.com \\ ${ }^{4}$ School of Architectural Engineering, Anhui University of Technology, Ma'anshan City 243002, Anhui Province, China
}

Abstract: With the rapid development of science and technology in our country, in order to comply with the trend of environmental protection, new requirements are put forward for the design of electrical energy saving of intelligent buildings in the process of urbanization. This paper mainly analyzes the significance of intelligent design of building electrical, analyzes the problems existing in the current intelligent technology design, and puts forward corresponding solutions to specific problems, hoping to provide some help to everyone in the intelligent design of building electrical, so as to promote the healthy development of electrical industry in China.

Keywords: Intelligent; Building Electrical; Energy Saving Engineering Design; Problem Discussion

\section{Introduction}

Through the relevant research, it can be seen that people pay more and more attention to the current living environment conditions. In this case, China's intelligent building electrical energy conservation project is born in time, so the relevant design requirements are higher and higher, but there are also some problems in the process of intelligent electrical development, if these problems can not be effectively solved, it will affect the good development of China's construction industry, so this paper through the detailed analysis of intelligent electrical, hoping to improve people's attention to it, so as to effectively improve the use efficiency in the construction process.

\section{Significance}

\subsection{The design can effectively improve the level of intelligent building electrical energy-saving technology in China, and promote the smooth completion of building related work}

Through reading the relevant literature, it can be seen that the intelligent electrical energy-saving technology is not mature enough in China, and there are still great deficiencies in the actual operation process, so the relevant staff through the continuous analysis and summary of the specific problems, which is conducive to the continuous progress of the intelligent electrical energy-saving technology in China, and the continuous improvement and progress of the technology. In the process, it can promote the holding of related activities,

\footnotetext{
Copyright (C) 2020 Jian Yin et al.

doi: 10.18282/adr.v2i1.873

This is an open-access article distributed under the terms of the Creative Commons Attribution Non-Commercial License

(http://creativecommons.org/licenses/by-nc/4.0/), which permits unrestricted non-commercial use, distribution, and reproduction in any medium, provided the original work is properly cited.
} 
so as to promote the development of the industry ${ }^{[1]}$.

\subsection{It can effectively reduce the use of energy in the construction industry}

The energy consumption of construction industry is always the largest and the main user of energy, so it is necessary to carry out the research of energy conservation activities. By carrying out the work related to electrical energy conservation, the staff can greatly improve the utilization rate of electrical in the construction industry, thereby reducing the energy consumption and promoting the long-term development of the construction industry.

\subsection{It can promote energy conservation and emission reduction and improve the economic benefits of the industry}

Under the background of the continuous development of the global economy, people pay more attention to their own economy, the higher the level of environmental quality requirements, and the higher the voice of protecting the environment through energy conservation and emission reduction. Therefore, the staff constantly improve their work ability, effectively complete the work content in the process of intelligent design, and promote the smooth progress of energy conservation and emission reduction. This can not only reduce the energy consumption of the construction industry, protect the environment, but also help enterprises to save costs, improve the economic benefits of enterprises and the whole industry, and contribute to the development of the national economy ${ }^{[2]}$.

To make a long strong short, it is very important for the construction industry to promote the development of intelligent electrical energy-saving projects.It can not only reduce the energy consumption of the construction industry, improve the utilization rate of energy in China, promote environmental protection, but also help the construction industry to save money and improve the overall economic benefits of the industry. In the long run, it can promote the long-term development of the construction industry in China, which is of irreplaceable significance.

\section{Existing problems}

In the process of promoting energy conservation and emission reduction technology in China, solar energy has gradually become an important part of energy in China, laying a solid foundation for the development of energy conservation projects in intelligent building electricity.

\subsection{Lack of a good monitoring system}

Generally speaking, for electrical energy conservation projects, it is necessary to start from the specific safety operation link for the goal of energy conservation and emission reduction, but through the specific investigation it is obvious that the domestic monitoring system in this aspect is not perfect, so the problems related to the quality and safety of electricity and gas often occur, which will pose a threat to the personal safety of the staff. At the same time, it will cause serious economic losses to the construction unit. The main reasons for the problems in the monitoring system of electrical energy-saving engineering in China are as follows: firstly, the staff of electrical energy-saving engineering design is lack, they do not have rich professional knowledge and practical experience, so it is difficult to design a relatively sound monitoring system; secondly, the complex characteristics of intelligent building electrical energy-saving engineering determine the relevant monitoring system is very hard to build.

\subsection{There is no matched electrical equipment to support the development of electrical energy conservation project}

In order to improve the overall level of building electrical energy-saving projects in China, enough attention should be paid to those small links. But in reality, in the specific research stage, the technology of electrical energy saving in China pays more attention to its economic benefits, which is also the reason why the quality of those equipment is very high, but it is difficult to play a role. At the same time, the purpose of electrical energy-saving projects in China is also to reduce the energy consumption of the construction industry and save energy. Therefore, high investment and low efficiency are the biggest problems in the design of electrical energy-saving projects in China. If this problem can not be effectively solved, even if the quality of additional equipment is no better, it can not promote 
the development of electrical energy-saving projects in China $^{[3]}$. Therefore, the relevant staff should put forward higher requirements for the relevant designers in the process of design, and constantly promote their own innovation ability, so as to promote the development of intelligent building electrical energy-saving engineering in China.

\subsection{There are big technical loopholes in the design of specific electrical energy-saving projects}

Intelligent building electrical energy-saving project is not an independent individual, it is composed of many parts together, so workers in the corresponding design activities, to carry out a unified and coordinated management. Because some of the current electrical energy-saving technology in China is not mature enough, it still has a lot of loopholes in the specific electrical energy-saving project, which leads to some problems. This kind of technical problem not only exists in some electrical energy-saving equipment, but also exists in the corresponding operational link, which will bring unnecessary waste to the electrical energy-saving project, and is not conducive to the establishment and development of the building electrical energy-saving system.

\section{Optimization measures}

In order to comply with the development of society, achieve the goal of energy conservation and emission reduction of intelligent building electrical energy conservation project, and achieve good results of both safety and energy consumption reduction in the specific work process, it is necessary to constantly optimize the relevant design of electrical energy conservation project, find corresponding solutions to specific problems, and promote the smooth development of the project.

\subsection{Establish a sound intelligent monitoring system in the right way}

A good monitoring system is very important for the electrical energy conservation project. First of all, a good monitoring system should be established according to the actual situation, which helps us to find the deficiencies in the process of work in time and take corresponding measures to solve them; Secondly, the intelligent control network in the project needs to be constantly optimized, through the recruitment of those professional and technical staff, let them check the deficiencies in the specific project to make up for the deficiencies. It is helpful to promote the effective development of the electric energy conservation project in China.

\subsection{Continuously develop corresponding energy-saving equipment}

Equipment is also essential for the development of the project, and the focus of our optimization of the equipment is mainly focused on the characteristics of energy saving, and the ultimate goal is to achieve energy saving and emission reduction. Therefore, designers need to constantly consider problems from the reality in the specific research and development process, through the research and discussion of various issues, to determine the most appropriate current situation of the device pattern. A good energy-saving equipment can make the staff get twice the result with half the effort in the specific work process.

\subsection{Continuously improve the quality and ability of designers}

The level of designers has a direct impact on the design of electrical engineering, so the comprehensive quality of the designers needs to be improved. First of all, the work unit can mainly employ some professional technical talents, such as college graduates; second, the work unit can carry out regular training, and constantly improve their professional skills.

\section{Conclusion}

In the process of the continuous development of the global economy, the application of intelligent electrical in the construction industry is essential, so relevant departments should pay enough attention to the design of intelligent building electrical energy-saving engineering.First of all, it is necessary to discuss the specific problems existing in the design, and then take corresponding measures to optimize the electrical energy-saving design, continuously enhance the coordination and management of electrical design in China, and improve the design level of the electrical design staff, so as to make contribution to the development of electrical energy-saving projects in 
China.

\section{References}

1. Kang J. Optimization design of electrical energy conservation in intelligent buildings (in Chinese). Engineering Technology Research 2017; (7): 206-207.
2. Liu Z, Tang Z. Optimization design and analysis of electrical energy conservation based on intelligent building (in Chinese). China High Tech Enterprise 2017; (1): 118-119. doi: 10.13535/j.cnki.11-4406/n.2017.01.057.

3. Xiao J. Optimization design of electrical energy conservation in intelligent buildings. Science and Technology and Enterprise 2015; (11): 107. doi: 10.3969/j.issn.1004-9207.2015.11.100. 